\title{
Electrostatic deposition of the oxidized kraft lignin onto surface on aminosilicas: thermal and structural characteristics of hybrid materials
}

Tetyana M. Budnyak ${ }^{1^{*}}$, Ievgen V. Pylypchuk ${ }^{1}$, Mikael E. Lindström ${ }^{1,2}$, Olena Sevastyanova ${ }^{1,2^{*}}$

1 KTH Royal Institute of Technology, Department of Fiber and Polymer Technology, Division of Wood Chemistry and Pulp Technology, Teknikringen 56-58, SE-100 44 Stockholm, Sweden

2 KTH Royal Institute of Technology, Department of Fiber and Polymer Technology, Wallenberg Wood Science Center (WWSC), Teknikringen 56-58, SE-100 44 Stockholm, Sweden

* Correspondence: tetyanabudnyak@yahoo.com, olena@kth.se; Tel.: +4687908067

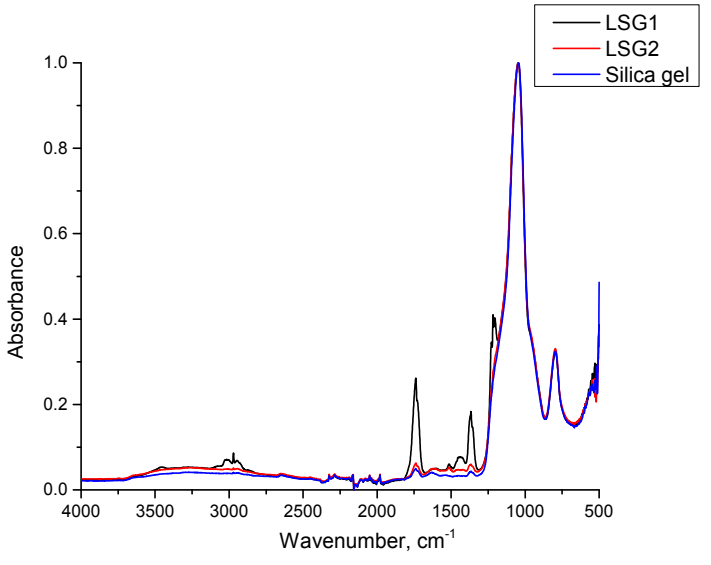

$a$

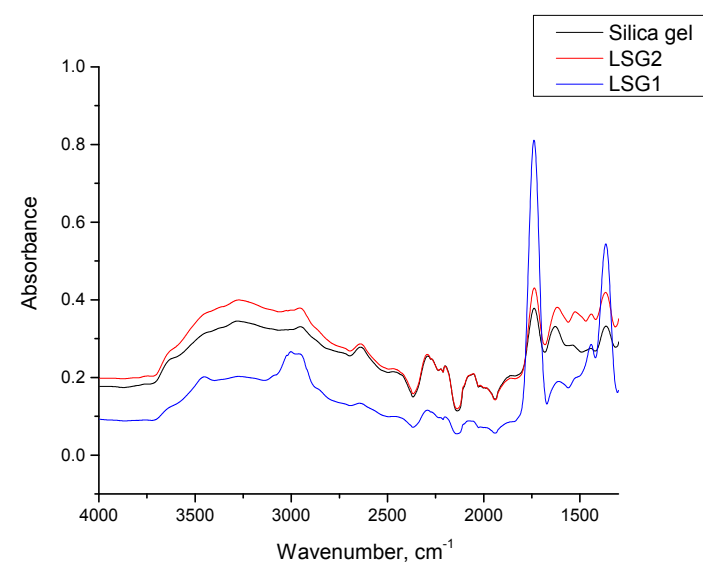

$c$

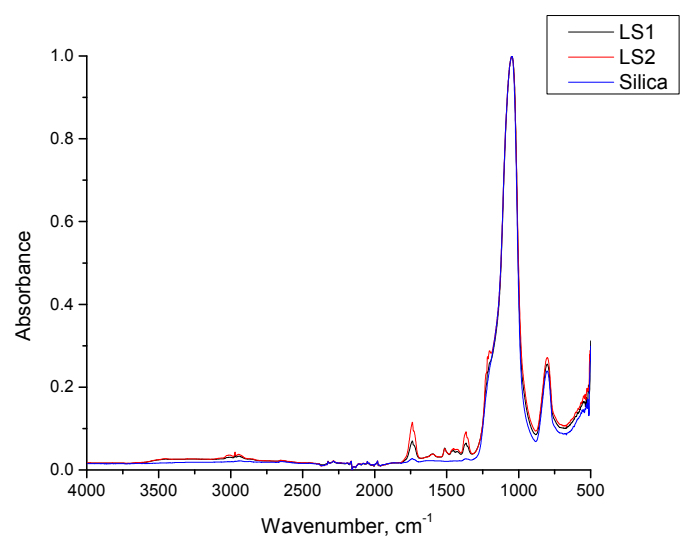

$b$

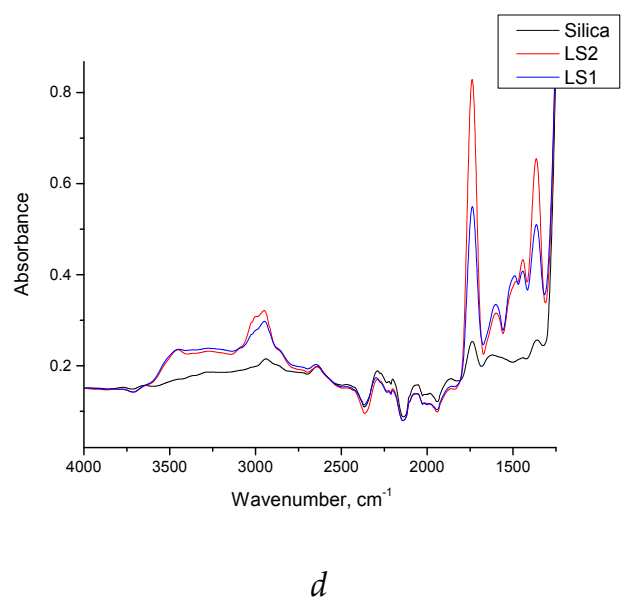

Figure S1. FTIR spectra of synthesized $(a, c)$ lignin-silica gel composites, $(b, d)$ lignin-silica composites and initial materials plotted at wavenumber ranges (a,b) 4000-500 $\mathrm{cm}^{-1}$ and (c,d) 4000$1250 \mathrm{~cm}^{-1}$. 


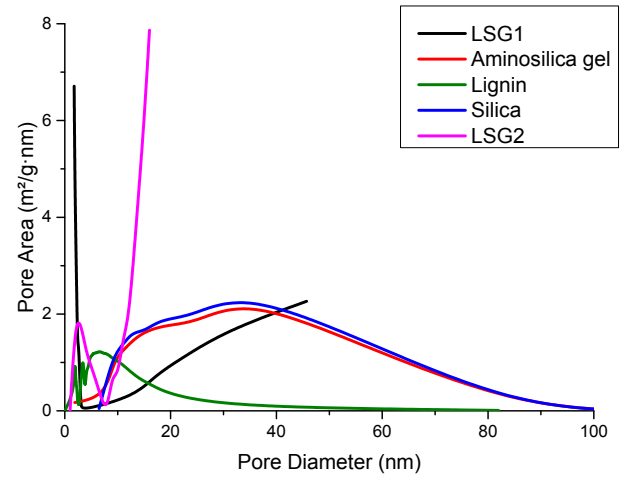

a

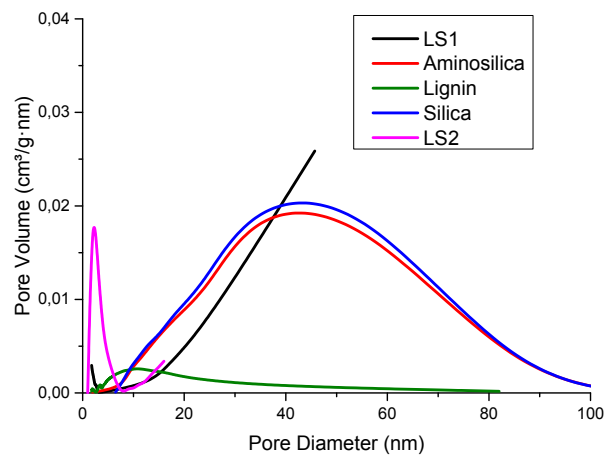

$\mathrm{b}$

Figure S2. Pore size distribution by area and volume for (a) lignin-silica gel, (b) lignin-silica and initial lignin, silica, aminosilica and aminosilica gel.
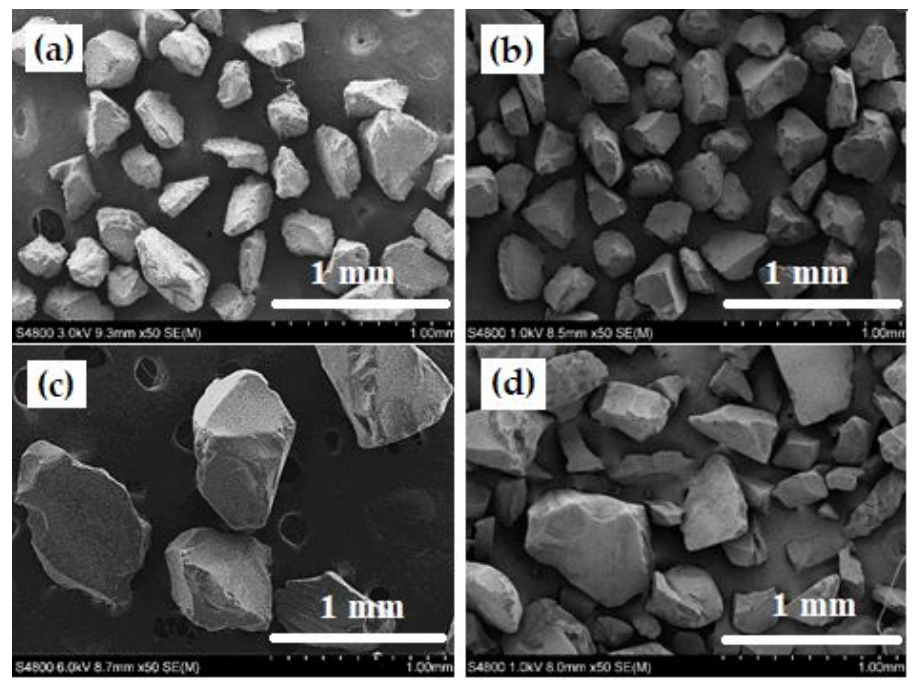

Figure S3. SEM images of LB-silica gel (a, b) and LB-silica composites (c, d). 